\title{
Phytophthora infestans Effectors IPI-O1 and IPI-O4 Each Contribute to Pathogen Virulence
}

\author{
Yu Chen and Dennis A. Halterman
}

First author: Department of Horticulture, University of Wisconsin, Madison 53706; and second author: U.S. Department of AgricultureAgricultural Research Service, Madison, WI 53726.

Accepted for publication 30 January 2017.

\begin{abstract}
Potato late blight, caused by the oomycete pathogen Phytophthora infestans, is one of the most destructive plant diseases. Despite decades of intensive breeding efforts, it remains a threat to potato production worldwide, because newly evolved pathogen strains have overcome major resistance genes quickly. The RB protein, from the diploid wild potato species Solanum bulbocastanum, confers partial resistance to most $P$. infestans strains through its recognition of members of the corresponding pathogen effector protein family IPI-O. IPI-O comprises a multigene family and while some variants are recognized by RB to elicit host resistance (e.g., IPI-O1 and IPI-O2), others are able to elude detection (e.g., IPI-O4). IPI-O1 is almost ubiquitous in global $P$. infestans strains while IPI-O4 is more rare. No direct experimental evidence has been shown to demonstrate the effect of IPI-O on pathogen

virulence in the $P$. infestans-potato pathosystem. Here, our work has demonstrated that in planta expression of both IPI-O1 and IPI-O4 increases $P$. infestans aggressiveness resulting in enlarged lesions in potato leaflets. We have previously shown that IPI-O4 has gained the ability to suppress the hypersensitive response induced by IPI-O1 in the presence of RB. In this study, our work has shown that this gain-offunction of IPI-O4 does not compromise its virulence effect, as IPI-O4 overexpression results in larger lesions than IPI-O1. We have also found that higher expression of IPI-O effectors correlates with enlarged lesions, indicating that IPI-O can contribute to virulence quantitatively. In summary, this study has provided accurate and valuable information on IPI-O's virulence effect on the potato host.
\end{abstract}

Coevolution between pathogens and plants has led to the development of a range of constitutive and inducible resistance mechanisms that help plants survive pathogen attack. Different models have been proposed to describe the plant immune system. The zigzag model describes a two-tiered plant defense system (Jones and Dangl 2006). The first layer of defense includes the recognition of certain pathogen structures (such as fungal chitin and bacterial flagellin or EF-Tu proteins) termed pathogen associated molecular patterns (PAMPs) by receptor proteins located on the surface of the host cell. Since these molecules are also present in nonpathogenic microbes, PAMPs have been often referred as MAMPs, microbe associated patterns (Ausubel 2005). This type of defense is called MAMP triggered immunity (MTI). The second layer of plant defense relies on the function of resistance (R) proteins that recognize specific pathogen molecules, termed effectors. Upon recognition, effector triggered immunity (ETI) is activated. Effectors operate outside pathogens and are highly variable in function and molecular structure. So far, both protein and RNA molecules have been found to serve as effectors (Wang et al. 2015). Some effectors are dispensable, either because they may have a minor virulence contribution to the pathogen or they are functionally redundant. Effectors are able to interfere with MTI or ETI through diverse strategies, enabling host colonization and leading to effector triggered susceptibility (ETS) (Asai and Shirasu 2015). ETI and ETS demonstrate a coevolutionary arms race between plants and pathogens. Generally, MTI and ETI activate

Corresponding author: D. A. Halterman;

E-mail address: dennis.halterman@ars.usda.gov

*The $\boldsymbol{e}$-Xtra logo stands for "electronic extra" and indicates that four supplementary figures and one supplementary file are published online.

This article is in the public domain and not copyrightable. It may be freely reprinted with customary crediting of the source. The American Phytopathological Society, 2017. similar defense responses, such as reprogramming of gene expression, production of oxidative molecules, MAP kinase signaling, and hormone signaling (Thomma et al. 2011; Tsuda and Katagiri 2010). ETI is typically stronger and faster than MTI, and is often associated with the hypersensitive response (HR), a rapid localized programmed cell death, which has the effect of limiting the development of a pathogen at the site of attack (Boller and He 2009; Dodds and Rathjen 2010).

Potato is the world's most important vegetable crop, with nearly 400 million tons produced worldwide every year, lending to stability in food supply and socioeconomic impact (National Potato Council 2016). Potato late blight is one of the most destructive plant diseases worldwide. This disease is caused by the oomycete pathogen Phytophthora infestans (Mont.) de Bary, which phenotypically resembles a fungus, but is more closely related to brown algae and diatoms (Kamoun et al. 2015). In the past several decades, two major outbreaks of potato late blight have occurred in the United States and Canada. The most recent outbreak, beginning in 2009, led to the distribution of $P$. infestans strains US22, US23, and US24. Since 2011, US23 has become increasingly dominant (Fry et al. 2015).

Within the past 15 years, rapid progress has been made in the identification and characterization of late blight $R$ genes and $P$. infestans effectors. For example, $R 1, R 2$, and $R 3 a$ have been cloned from Solanum demissum (Ballvora et al. 2002; Huang et al. 2005; Lokossou et al. 2009). RB (also known as Rpi-blb1), Rpi-blb2, and Rpi-blb3 have been cloned from $S$. bulbocastanum (Lokossou et al. 2009; Song et al. 2003; van der Vossen et al. 2003; Vossen et al. 2005). Rpi-vnt1.1 has been cloned from $S$. venturii (Foster et al. 2009; Pel et al. 2009), and Rpi-mcq1 gene has been cloned from S. mochiquense (Jones et al. 2013). These R proteins all provide resistance to individual or multiple strains of $P$. infestans, and share the same CC-NB-LRR (coiled-coil, nucleotide binding, leucinerich repeat) structure.

Genome sequencing of multiple Phytophthora species, such as $P$. infestans, $P$. sojae, and P. ramorum, has led to the identification of 
effectors with highly conserved RXLR and dEER motifs. The RXLR motif is important in entry of these effectors into the host cytoplasm, although the mechanism by which this occurs is currently under debate (Petre and Kamoun 2014). Many RXLR effectors have been exploited to study the mechanisms by which $P$. infestans manipulates host immunity. The focus of the present study is the $P$. infestans RXLR effector IPI-O (also known as Avrblb1). IPI-O is a multigene family of effectors. This family shares a cell attachment motif ArgGly-Asp (RGD), and it has been reported that IPI-O may modulate host immunity by disrupting host cell wall and plasma membrane adhesions through interaction with the host lectin receptor kinase LecRK-I.9 (Bouwmeester et al. 2011; Senchou et al. 2004). It was previously determined that this effector family consisted of at least two closely related members, IPI-O1 and IPI-O2 (Pieterse et al. 1994), which are induced in planta during the early stage of $P$. infestans infection, supporting a likely role of this gene family in pathogenesis (van West et al. 1998). Sequencing of $I P I-O$ from other $P$. infestans strains revealed that the IPI-O locus could be extremely variable between pathogen strains (Champouret et al. 2009; Halterman et al. 2010). IPI-O variants have been divided into three classes based on diversity of their deduced amino acid sequences. Class I and class II variants (e.g., IPI-O1) are found in the majority of $P$. infestans strains, and are recognized by the RB protein to elicit ETI. In contrast, class III variants (e.g., IPI-O4) are more rare, and are able to elude the recognition of RB (Champouret et al. 2009; Halterman et al. 2010). We have previously shown that the presence of IPI-O4 in planta is able to suppress the HR elicited by IPI-O1 in the presence of RB (Chen et al. 2012; Halterman et al. 2010). We also found that $P$. infestans strains with a relatively large number of IPI-O variants are more virulent on susceptible leaves than those with fewer variants, and these more virulent strains contain IPI-O4, whereas the less virulent strains do not (Halterman et al. 2010). In other words, the aggressiveness of $P$. infestans strains was correlated with increased IPI-O diversity and especially the presence of the IPI-O4 variant, but not IPI-O1. It is unclear at this point whether the ability of these strains to cause more severe disease symptom is due to the presence of multiple IPI- $O$ genes, the presence of IPI-O4, or another unidentified factor. A contribution to virulence by IPI-O has been suggested in previous research (Bouwmeester et al. 2011; van West et al. 1998), however previous assays to determine this effect were focused on the protein's interaction with LecRK-I.9 in the apoplast. Since we have previously shown the potential for IPI-O to affect cytoplasmic proteins (e.g., RB), our current study is focused on determining the effect of expression of IPI-O1 and IPI-O4 on P. infestans virulence within the plant cell.

\section{MATERIALS AND METHODS}

Potato transformation and identification of positive transformants. In order to assay the effect of in planta expression of IPI-O genes, we introduced IPI-O1 and IPI-O4 into susceptible potato cultivar Katahdin separately through stable transformation. Agrobacterium tumefaciens strain GV3101 containing N-terminal Myc-tagged IPI-O1 or IPI-O4 in a gateway binary vector pGWB18 (Chen et al. 2012) was used for transformation. Internode explants from in vitro Katahdin plantlets were transformed following a standard A. tumefaciens-mediated potato (Solanum tuberosum) transformation procedure (Bhaskar et al. 2008). Control (wild-type) Katahdin explants were not treated with Agrobacterium and were propagated on media lacking antibiotics.

Both wild-type and transgenic Katahdin plants were propagated from cuttings and maintained in the greenhouse, which was set for $14 \mathrm{~h}$ of daylight, a daytime temperature of $23^{\circ} \mathrm{C}$, and a nighttime temperature of $15^{\circ} \mathrm{C}$. Genomic DNA was extracted from leaf tissue using the Qiagen (Hilden, Germany) DNeasy Plant Mini Kit. The oligonucleotides MycIPI-O1F1 (5'-TGAACGGACTCGACGGTGAA-3') and MycIPIO1R1 (5'-GACGTGTTGGGCTCTTTTGTGA-3') were used in a PCRbased screen for the presence of the IPI-OI gene, and the oligonucleotides
MycIPI-O1F3 (5'-AGAAGACTTGAACGGACTCG-3') and MycIPIO4R1 (5'-CCGTGTTGGGCTCTTTTGTGAC-3') were used to screen the presence of the IPI-O4 gene in transgenic Katahdin candidates, respectively. The PCR conditions were as follows: $1 \mathrm{~min}$ at $94^{\circ} \mathrm{C}$ followed by 35 cycles of $15 \mathrm{~s}$ at $94^{\circ} \mathrm{C}, 30 \mathrm{~s}$ at $55^{\circ} \mathrm{C}, 30 \mathrm{~s}$ at $68^{\circ} \mathrm{C}$, and $7 \mathrm{~min}$ at $68^{\circ} \mathrm{C}$.

Seven IPI-O1 positive transgenic Katahdin candidates A, C, D, G, $\mathrm{Z}, \mathrm{CC}$, and LL and seven IPI-O4 positive transgenic Katahdin candidates $\mathrm{M}, \mathrm{O}, \mathrm{P}, \mathrm{CC}, \mathrm{DD}, \mathrm{FF}$, and GG were selected for protein blotting to verify the expression of IPI-O. To prepare total protein, 4 -week-old wild type or IPI-O transgenic Katahdin leaves were ground in liquid nitrogen. One hundred milligrams of leaf powder was thawed and boiled in $200 \mu \mathrm{l}$ of $4 \times$ SDS-PAGE loading buffer (200 mM Tris-Cl [pH 6.8], 400 mM DTT, 8\% SDS, 40\% glycerol) for $5 \mathrm{~min}$. The suspension was centrifuged for $5 \mathrm{~min}$ at room temperature at $16,000 \times g$. The supernatant was added to an equal volume of $2 \times$ SDS-PAGE loading buffer ( $100 \mathrm{mM}$ Tris-Cl [pH 6.8], $200 \mathrm{mM}$ DTT, 4\% SDS, $20 \%$ glycerol), and boiled for $5 \mathrm{~min}$. After a 5 min centrifuge at room temperature at $16,000 \times g, 30 \mu$ of the supernatant was resolved on a $12 \%$ SDS-PAGE gel and transferred to PVDF (GE Healthcare, Little Chalfont, UK) according to the manufacturer's recommendations. Protein was detected using an anti-Myc antibody (Roche, Basel, Switzerland) with an ECL western blotting detection system (Thermo Fisher Scientific, Waltham, MA) according to the manufacturer's instructions. In order to compare the IPI-O protein expression level in each transgenic line, densitometric quantification of western blotting signals was measured with Image Lab Software (Bio-Rad, CA), and normalized by Ponceau S staining (Romero-Calvo et al. 2010). Protein quantification with each transgenic line was performed three times independently. All three sets of data were used for correlational analysis between IPI-O protein expression level and lesion size. The mean of the three sets of data were used to generate the scatter plots.

$P$. infestans strains and host inoculation. Three $P$. infestans strains GU68, US23, and US24 and were used for inoculation assays. US23 and US24 were kindly provided by A. Gevens (University of Wisconsin, Madison), and GU68 (originally isolated in Guatemala) was maintained in our lab (Halterman et al. 2010). Wild-type Katahdin, five IPI-O1, and five IPI-O4 transgenic Katahdin plants were used in a detached leaflet assay. Leaflets of the first, second, and third leaves below the uppermost fully expanded leaf were harvested from 4- to 5-week-old plants and inoculated with one $10 \mu \mathrm{l}$ drop of $P$. infestans sporangia solution or water on the right side of the midvein, on the lower surface of the leaf, in approximately the same location. To obtain sporangia, mycelia growing on Rye A media were flooded with sterilized water and gently rubbed with a sterile glass rod. The concentration of the sporangia solution for the three strains was: GU68, 10,000 sporangia/ml; US23, 75,000 sporangia/ml; and US24, 75,000 sporangia/ml. The leaves were then placed upside down in a petri dish with a wet filter paper at the bottom. The petri dishes containing the leaves were kept in a growth chamber at $16^{\circ} \mathrm{C}$. Ten leaves were collected from each wild type or IPI-O transgenic Katahdin line. The whole inoculation experiment was performed three times. Digital images of the inoculated leaflets were obtained 6 days after inoculation with a scanner. Lesion area was measured using Image $\mathbf{J}$ (Schneider et al. 2012). Statistical analysis was done with $\mathrm{R}$ version 3.1.2 platform using fixed linear model and multiway ANOVA. Comparison was determined using Tukey's SHD at $P=0.05$. ANOVA tables are included as Supplementary File S1.

Cloning of IPI-O from $P$. infestans strains US23 and US24. Genomic DNA of $P$. infestans was purified using a Fast DNASPIN for Soil Kit (MP Biomedicals, LLC, OH). Using this DNA as a template, IPI-O was amplified using Platinum PCR SuperMix High Fidelity (Invitrogen, Carlsbad, CA) and a pair of oligonucleotide primers: RD6F (5'-CGCATCGATGGTTTCATC CAATCTCAACACCGCCG-3') and RD6R (5'-GATGCGGCCGC 
TATACGATGTCATAGCATGACA-3'). The PCR conditions were as follows: $1 \mathrm{~min}$ at $94^{\circ} \mathrm{C}$ followed by 30 cycles of $15 \mathrm{~s}$ at $94^{\circ} \mathrm{C}, 30 \mathrm{~s}$ at $55^{\circ} \mathrm{C}, 30 \mathrm{~s}$ at $68^{\circ} \mathrm{C}$, and $7 \mathrm{~min}$ at $68^{\circ} \mathrm{C}$. The PCR product was purified using a gel DNA recovery kit (Zymo Research, Irvine, CA) and ligated into pGEM-T Easy Vector (Promega, Madison, WI), which was then transformed into E. coli. Forty-eight plasmid clones containing IPI-O variants from each strain were sequenced in both directions using vector-specific primers. Poisson distribution was used to ensure that the cumulative probability of finding all variants was greater than $99 \%$. Double-strand sequencing of DNA was carried out at the University of Wisconsin-Madison Biotechnology Center sequencing facility. Vector sequence removal was performed using DNASTAR software (Madison, WI). Duplicate identical sequences from the same $P$. infestans strain were removed from the analysis.

\section{RESULTS}

Identification of positively transformed Katahdin with IPI-O. In order to screen for the presence of IPI-O in transgenic Katahdin candidates, primer sets for both IPI-O1 and IPI-O4 were designed with a 5' primer located within the Myc tag area and a 3' primer located within IPI-O. A total of 20 IPI-O1 and 20 IPI-O4 transgenic Katahdin candidates were screened with the corresponding primer set. An expected 280-bp band was observed in all IPI-O containing lines, but not in nontransformed or a number of transformed Katahdin plants lacking the transgene (Supplementary Fig. S1). Seven IPI-O1 and 7 IPI-O4 lines were randomly selected for the verification of IPI-O protein expression using western blotting. Protein expression of IPI-O was confirmed by visualization of an expected 25-kDa band after detection with an anti-Myc antibody (Fig. 1). A longer exposure of the western blot image of IPI-O1 transgenic lines is shown in Supplementary Fig. S2.

IPI-O variants in $P$. infestans strains GU68, US23, and US24. Three $P$. infestans strains GU68, US23, and US24, were used to assay the effect of in planta expression of IPI-O on the ability of $P$. infestans to cause disease symptoms on potato plants. In order to properly analyze our results, it was important to know what endogenous IPI-O variants are present in these strains. The IPI-O variants present in GU68 and the aggressiveness of this strain has been well characterized in our previous research (Halterman et al. 2010). In brief, 14 unique IPI-O sequences were identified in GU68. Ten, 3, and 1 of them belong to class I, class II, and class III, respectively (Halterman et al. 2010). This strain was the most virulent strain tested on Katahdin plants (Halterman et al. 2010). In the present study, we used the same method to identify IPI-O variants in US23 and US24. In line with the previous results, the PCR products were $456 \mathrm{bp}$ fragments, which lack the region encoding the signal sequence but contain DNA encoding the RXLR motif and the remainder of the protein, as well as a portion of the 39 bp $3^{\prime}$ untranslated region. In summary, we obtained eight unique deduced IPI-O amino acid sequences from US23 sharing a similarity of 84.1 to $99.3 \%$. Seven of the IPI-O variants belong to class I, and one of them belongs to class III (Supplementary Fig. S3). In US24 we obtained 14 unique deduced amino acid sequences sharing a similarity of 82.7 to $99.3 \%$. Thirteen of the variants belong to class I, and one of them belongs to class III. We did not obtain any class II variants of IPI-O.

Effect of IPI-O1 and IPI-O4 on P. infestans virulence. All the independent transgenic Katahdin lines we have obtained did not show any visible morphological difference from wild-type Katahdin. Five independent IPI-O1 transgenic Katahdin lines (A, $\mathrm{C}, \mathrm{D}, \mathrm{G}$, and CC) and five independent IPI-O4 transgenic Katahdin lines (M, O, P, FF, and GG) were selected for inoculation assays. Three $P$. infestans strains (GU68, US23, and US24) were used to inoculate the potato plants. The inoculation results varied with different strains. When inoculated with GU68, the average lesion size in IPI-O1 transgenic leaves was significantly larger than that in the wild-type leaves $(P=0.0005)$; the average lesion size in IPI-O4 transgenic leaves was also significantly larger than that in the wildtype leaves $(P=0.0398)$; there was no significant difference of lesion size between IPI-O1 and IPI-O4 transgenic plants $(P=$ 0.1627) (Fig. 2A). When inoculated with US23, IPI-O1 transgenic leaves showed significantly larger lesions than wild-type leaves $(P=0.0090)$. IPI-O4 transgenic leaves also showed significantly larger lesions than the wild-type leaves $(P<0.0001)$. The average lesion size in IPI-O4 transgenic leaves was significantly larger than that in the IPI-O1 transgenic leaves $(P=0.0007)$ (Fig. 2B). When inoculated with US24, no significant difference was detected between IPI-O1 transgenic leaves and the wild-type leaves $(P=$ $0.1223)$, or IPI-O4 transgenic leaves and the wild-type leaves $(P=$ 0.8142 ). However, the average lesion size in IPI-O4 transgenic leaves was significantly larger than that in the IPI-O1 transgenic leaves $(P=0.0030)$ (Fig. 2C).

Virulence comparisons between GU68, US23, and US24. The data we obtained from this study also allowed us to compare the virulence among the strains on compatible hosts. First, we extracted data from all wild-type plants, and compared the lesion size among them when inoculated with GU68, US23, or US24. The result showed that GU68 was the most virulent, followed by US23, and US24 (GU68 versus US23, $P=0.0029$; GU68 versus US24, $P=$ 0.0000 ; and US23 versus US24, $P=0.0232$; Fig. 3A). Next we did the same analysis with the subset data from IPI-O1 or IPI-O4 transgenic potato lines separately. Similarly, in IPI-O1 transgenic leaves, GU68 caused the largest lesions, followed by US23 and US24 (GU68 versus US23, $P=0.0000$; GU68 versus US24, $P=0.0000$; and US23 versus US24, $P=0.000$; Fig. $3 \mathrm{~B}$ ). The same result was obtained with IPI-O4 transgenic plants. GU68 caused the
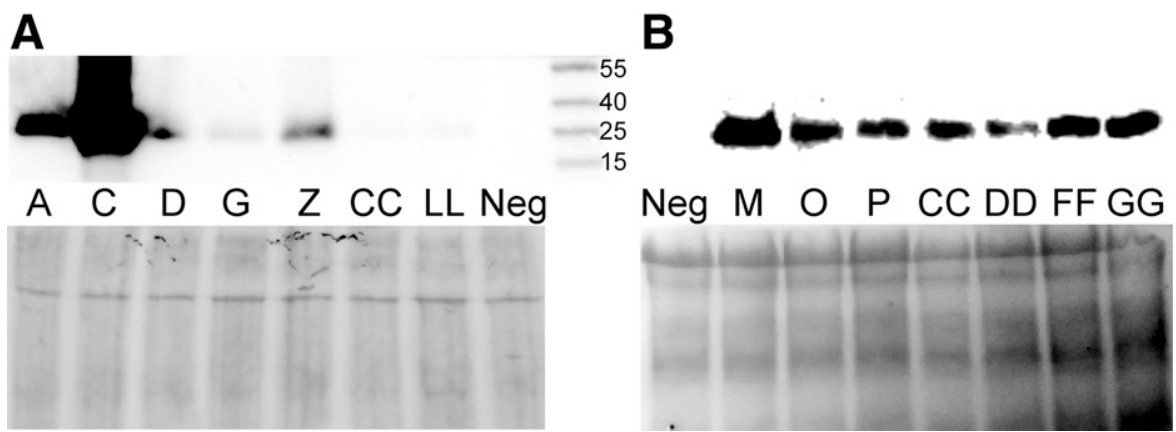

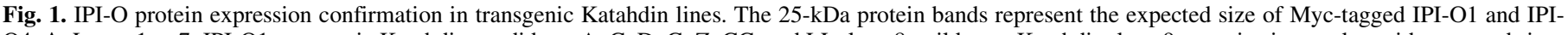

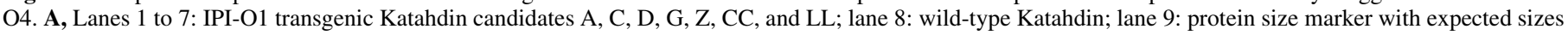

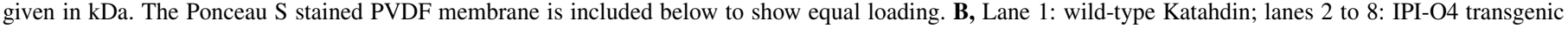
Katahdin candidates M, O, P, CC, DD, FF, and GG. The Ponceau S stained PVDF membrane is shown below to demonstrate equal loading. 
largest lesions, followed by US23 and US24 (GU68 versus US23, $P=0.0863$; GU68 versus US24, $P=0.0000$; and US23 versus US24, $P=0.000 ;$ Fig. 3C).

Protein expression level of IPI-O correlates with lesion size. In order to determine whether the protein expression level of IPI-O correlates with lesion size, we have compared the lesions and IPI-O protein expression levels between independent IPI-O1 or IPI-O4 transgenic individuals. The results showed a correlation between lesion size and IPI-O1 protein accumulation when inoculated with GU68 (Table 1). Correlation was not observed when inoculated with US23 or US24 in IPI-O1 transgenic lines, nor in IPI-O4 transgenic lines inoculated with any P. infestans strains. Although this correlation was only observed in IPI-O1 transgenic lines when inoculated with GU68, we found an association between small lesions and low IPI-O protein levels. The IPI-O1 transgenic individual $\mathrm{CC}$ had the lowest protein expression level compared with the other lines (Supplementary Fig. S4). This line had the smallest lesion size when inoculated with GU68 (C versus CC, $P=$ 0.0028; Fig. 4A) and US23 (C versus CC $P=0.0017$; D versus $C C$, $P=0.0185$; Fig. 4B). The IPI-O4 transgenic individual $\mathrm{P}$ had the lowest protein expression level compared with other lines. This line also had the smallest lesion size when inoculated with GU68 (FF versus $\mathrm{P}, P=0.0075$; $\mathrm{M}$ versus $\mathrm{P}, P=0.0021$; $\mathrm{O}$ versus $\mathrm{P}, P=0.0219$; Fig. 4D), US23 (FF versus $P, P=0.0443$; GG versus $P, P=0.0005$; $M$ versus $P, P=0.0007$; Fig. $4 \mathrm{E}$ ), and US24 (FF versus $\mathrm{P}, P=0.0485$; $\mathrm{O}$ versus $\mathrm{P}, P=0.0122$; Fig. $4 \mathrm{~F})$.

\section{DISCUSSION}

Successful infection by a plant pathogen is determined by its ability to overcome host defenses or escape host surveillance. A major function of pathogen effectors is to suppress MTI or ETI and
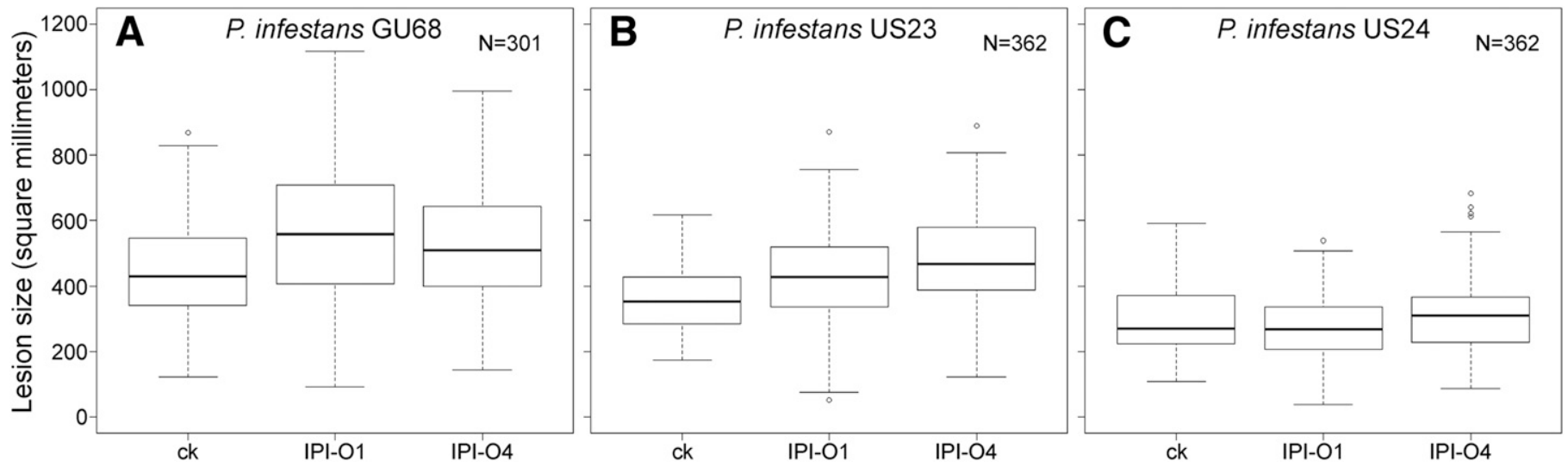

Fig. 2. Lesion size comparison among wild-type Katahdin, IPI-O1 transgenic Katahdin, and IPI-O4 transgenic Katahdin plants. A, Plants were inoculated with Phytophthora infestans strain GU68. B, Plants were inoculated with P. infestans strain US23. C, Plants were inoculated with $P$. infestans strain US24. Measurements were taken 6 days postinoculation. The experiment was repeated three times.
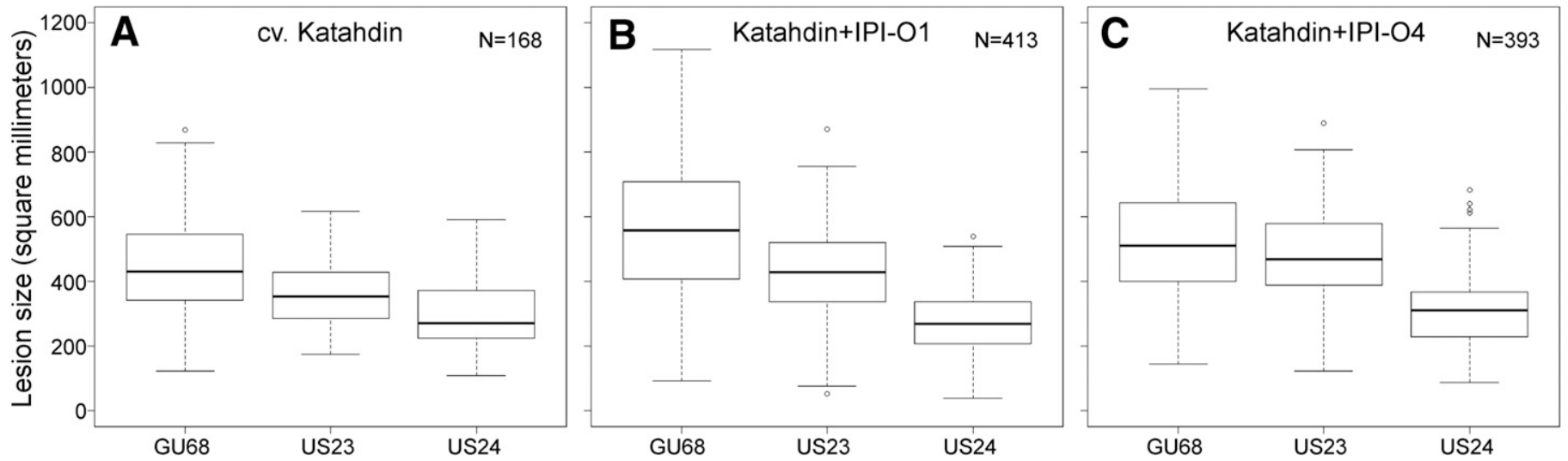

Fig. 3. Virulence comparison among Phytophthora infestans strain GU68, US23, and US24. A, Lesion size comparison with wild-type Katahdin. B, Lesion size comparison with IPI-O1 transformed Katahdin. C, Lesion size comparison with IPI-O4 transformed Katahdin. Measurements were taken 6 days postinoculation. The experiment was repeated three times.

TABLE 1. Correlation between IPI-O protein expression level and lesion size

\begin{tabular}{|c|c|c|c|c|c|c|}
\hline \multirow[b]{3}{*}{ Effector } & \multicolumn{6}{|c|}{ Phytophthora infestans strain } \\
\hline & \multicolumn{2}{|l|}{ GU68 } & \multicolumn{2}{|l|}{ US23 } & \multicolumn{2}{|l|}{ US24 } \\
\hline & Correlation coefficient & $P$ value ${ }^{\mathrm{a}}$ & Correlation coefficient & $P$ value ${ }^{a}$ & Correlation coefficient & $P$ value $^{\mathrm{a}}$ \\
\hline IPI-O4 & 0.7338 & 0.1581 & 0.7475 & 0.1464 & 0.2367 & 0.7015 \\
\hline
\end{tabular}

a The level of significance was set at $P<0.05$. 
promote colonization (Rovenich et al. 2014). Some effectors have evolved to elude recognition by the host cognate $\mathrm{R}$ protein through mutation or deletion (Karasov et al. 2014). The P. infestans multigene IPI-O effector family is a typical case of the combination of the two scenarios. IPI-O4 can circumvent recognition by the RB protein and is capable of inhibiting the HR induced by IPI-O1 (Chen et al. 2012; Halterman et al. 2010). A similar example is the P. infestans effector PexRD2 (Boutemy et al. 2011), which is a member of a family of 18 RXLR-type effector proteins (Haas et al. 2009). It interacts with the kinase domain of MAPKKKe, a positive regulator of plant cell death, and thus interferes with host immunity (King et al. 2014). PexRD2 supports enhanced $P$. infestans growth in Nicotiana benthamiana leaves, while its naturally occurring or engineered variants, which no longer interact with MAPKKKe, fail to promote the in planta growth of $P$. infestans (King et al. 2014), indicating a reduction in virulence. Another example is the P. infestans effector AVR3a. Two alleles of this effector, AVR3aKI and AVR3aEM, have contrasting phenotypes in terms of interaction with the host. AVR3aKI, but not AVR3aEM, activates potato R protein R3a to trigger ETI (Armstrong et al. 2005). In addition, both forms suppress programmed cell death induced by the $P$. infestans elicitin INF1; AVR3aKI does so strongly, whereas suppression by AVR3aEM is weak (Bos et al. 2006, 2009). Interestingly, AVR3aKI and AVR3aEM contribute equally to virulence (Bos et al. 2010). In contrast, AVR3a in P. infestans strain R0 does not contribute to virulence due to its low transcription level regulated by sRNA silencing (Vetukuri et al. 2012). Members of the IPI-O family of effectors appear to have dual functions in virulence in different regions of the host cell. Interaction of IPI-O with the lectin receptor kinase LecRK-I.9 in the apoplast disrupts plasma membrane-cell wall interactions, which leads to increased susceptibility to $P$. brassicae in Arabidopsis (Bouwmeester et al. 2011). Our present work has shown that over-expression of both IPI-O1 and IPI-O4 lacking signal peptides assist $P$. infestans to make enlarged lesions in potato leaves. This effect presumably takes place within the host cytoplasm. Previously, we have found that IPI-O4 has gained the ability to elude recognition by the RB protein and suppresses the HR induced by IPIO1 in the presence of RB (Chen et al. 2012; Halterman et al. 2010). In this study, our work has demonstrated that this gain-of-function of IPI-O4 does not compromise its virulence effect. In addition, IPI-O4 assists some $P$. infestans stains to make larger lesions than IPI-O1. This result is in line with our previous observation that IPI-O4 is associated with higher $P$. infestans aggressiveness (Halterman et al. 2010).

Oomycete pathogens have the capacity to produce hundreds of effectors. Some effectors are not crucial; deletions or frame shift mutations do not affect virulence or pathogenicity (van Poppel et al. 2008). Other effectors, however, seem to be indispensable (Bos et al. 2010; Liu et al. 2011). Gene silencing has been used as an efficient method to identify virulence-essential effectors. For example, when the transcription level of $P$. sojae RXLR effector Avh241 was reduced to $40 \%$ of the wild type, the silenced $P$. sojae lines showed a significant reduction in virulence (Yu et al. 2012). As another example, when the transcription level of $P$. sojae CRN effector PsCRN63 and PsCRN115 were reduced to about 20 and $40 \%$ relative to the wild type, respectively, the silenced $P$. sojae lines caused decreased lesion sizes (Liu et al. 2011). These examples have provided the evidence that some effectors can contribute to virulence quantitatively. Here, our results have provided another line of evidence by over-expression of the effector instead of gene silencing to support our conclusions. Through overexpression of the IPI-O effectors in every cell of the host, rather than silencing
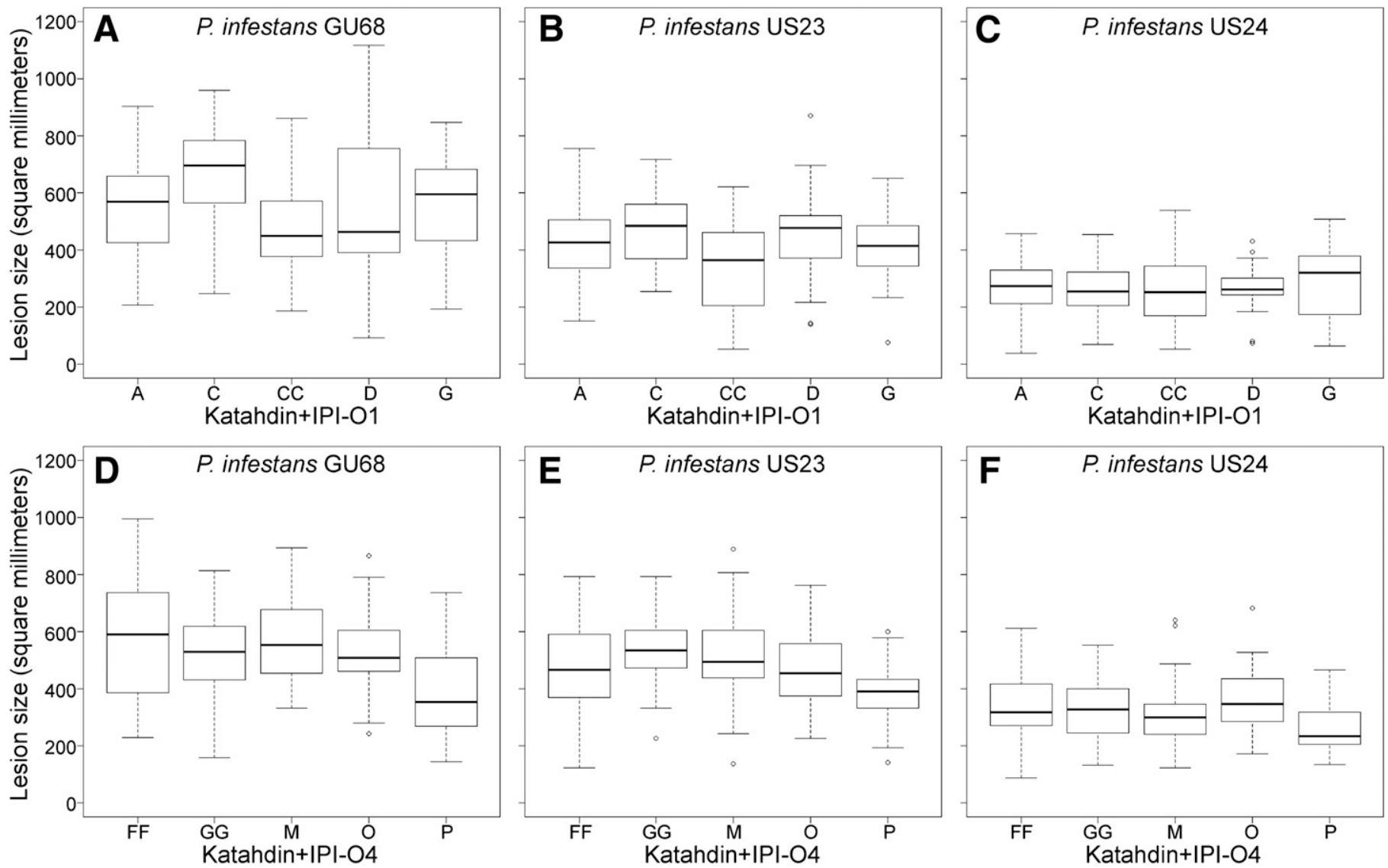

Fig. 4. Lesion size comparison among independent IPI-O transgenic Katahdin individuals. A to C, Lesion size comparison among IPI-O1 transgenic individuals inoculated with GU68, US23, and US24, respectively. D to F, Lesion size comparison among IPI-O4 transgenic individuals inoculated with GU68, US23, and US24, respectively. Measurements were taken 6 days postinoculation. The experiment was repeated three times. 
expression in the pathogen, we were able to determine a quantitative and significant role of these genes in P. infestans virulence. Furthermore, the introduction of a tagged effector gene in the host will allow for future experiments to determine what host proteins might be targets for IPI-O.

In this study, we have assayed five independent transgenic lines for both IPI-O1 and IPI-O4. By quantitating IPI-O protein levels in these plants, we found that IPI-O1 expression level in the host correlates with pathogen lesion size when inoculated with GU68, although this correlation is not linear (i.e., a several fold higher protein expression level does not result in the same relative increase in lesion size). Among the five IPI-O1 expressing lines, the line CC had the lowest expression level. This lower expression associated with smaller lesion size, and the results are consistent with all the three $P$. infestans strains tested. We observed the same phenomenon with IPI-O4 transgenic lines. The transgenic line $\mathrm{P}$ had a relatively lower protein expression level than others, and the average lesion sizes on this line were significantly smaller than other lines. Together, these results suggest that, within the protein expression range tested in this study, a higher amount of IPI-O effectors correlates with enlarged lesions. It is important to note, however, that overexpression of pathogen effectors in plants likely does not reflect the amount of protein found during natural infection. For this reason, it is difficult to interpret the effect that differences in IPI-O effector expression can have on disease lesion size.

Our previous research has shown that the RB protein may interact with IPI-O directly, and IPI-O4 may suppress RB-mediated resistance through competition with IPI-O1 (Chen et al. 2012; Halterman et al. 2010). In addition, expression of RB is closely correlated with resistance, as RB transgenic plants with multiple integration events are more resistant than those with fewer copies of RB (Bradeen et al. 2009; Kramer et al. 2009). Taken together with our conclusion that expression of corresponding effectors from the pathogen could affect virulence, these results provide valuable information for potato breeding against late blight. Pyramiding of $R$ genes that recognize different effectors, combined with increasing expression of the $R$ genes could be a more effective strategy to combat $P$. infestans, especially in the case of RB-related potato breeding.

The transgenic plants we have generated in this study did not show any morphological difference from the wild type. This indicates that over-expression of either IPI-O or IPI-O4 alone does not harm the plants. One of the reasons could be that in planta expressed IPI-O has to work with specific partners from $P$. infestans to impact the pathogen's ability to cause symptoms. Three $P$. infestans strains GU68, US23, and US24, were used for inoculation assay in this study. The three strains vary in aggressiveness with GU68 being the most aggressive. Following inoculation with GU68, the effect of IPI-O over-expression on lesion development was obvious. However, a difference between IPI-O1 and IPI-O4 was not observed (Fig. 3A). US23 is a moderately aggressive strain. When inoculated with this strain, the effect of IPI-O on lesion development is clear, and it is also clear that IPI-O4 caused larger lesions than IPI-O1 (Fig. 3B). US24 is the least aggressive strain. When inoculated with US24, IPI-O did not promote enlarged lesions compared with the wild-type host. However, it is important to note that IPI-O4 helped to cause larger lesions than IPI-O1 (Fig. 3C). These results indicate that the effect of IPI-O expression is dependent on the genetic background of the particular $P$. infestans clonal lineage. We can conclude therefore that aggressive strains benefit from IPI-O more. Related research has shown that the performance of effectors not only varies with different pathogen strains but can also depend on the host used for the resistance assay (Fabro et al. 2011). In the study by Fabro and colleagues, the authors delivered 64 putative Hyaloperonospora arabidopsidis RXLR type effectors via Pseudomonas syringae type-three secretion system into 12 Arabidopsis thaliana accessions and Brassica rapa (turnip). The results showed that the performance of the effectors was host specific (Fabro et al. 2011). Most likely it is because the host targets of the effectors have diverged. With respect to $P$. infestans, we would therefore expect that the effect of IPI-O variants on virulence on other hosts, such as tomato, could be different.

In this study, we have generated stable transformed potato plants with IPI-O effectors from $P$. infestans. The results from this study have provided accurate and valuable information on the effector's impact on virulence in a potato host. Our experiments were conducted in the absence of the corresponding $R B$ host resistance gene. As our previous results have shown that IPI-O4 compromises hypersensitive cell death mediated by RB (Chen et al. 2012; Halterman et al. 2010), future experiments done using plants containing this $R$ gene could provide valuable information regarding the ability of $P$. infestans to overcome resistance.

\section{LITERATURE CITED}

Armstrong, M. R., Whisson, S. C., Pritchard, L., Bos, J. I., Venter, E., Avrova, A. O., Rehmany, A. P., Bohme, U., Brooks, K., and Cherevach, I. 2005. An ancestral oomycete locus contains late blight avirulence gene Avr3a, encoding a protein that is recognized in the host cytoplasm. Proc. Natl. Acad. Sci. USA 102:7766-7771.

Asai, S., and Shirasu, K. 2015. Plant cells under siege: Plant immune system versus pathogen effectors. Curr. Opin. Plant Biol. 28:1-8.

Ausubel, F. M. 2005. Are innate immune signaling pathways in plants and animals conserved? Nat. Immunol. 6:973-979.

Ballvora, A., Ercolano, M. R., Weiss, J., Meksem, K., Bormann, C. A., Oberhagemann, P., Salamini, F., and Gebhardt, C. 2002. The Rl gene for potato resistance to late blight (Phytophthora infestans) belongs to the leucine zipper/NBS/LRR class of plant resistance genes. Plant J. 30: 361-371.

Bhaskar, P., Raasch, J., Kramer, L., Neumann, P., Wielgus, S., Austin-Phillips, S., and Jiang, J. 2008. Sgt1, but not Rarl, is essential for the $R B$-mediated broad-spectrum resistance to potato late blight. BMC Plant Biol. 8:8.

Boller, T., and He, S. Y. 2009. Innate immunity in plants: An arms race between pattern recognition receptors in plants and effectors in microbial pathogens. Science 324:742-744.

Bos, J. I., Chaparro-Garcia, A., Quesada-Ocampo, L. M., Gardener, B. B. M., and Kamoun, S. 2009. Distinct amino acids of the Phytophthora infestans effector AVR3a condition activation of R3a hypersensitivity and suppression of cell death. Mol. Plant-Microbe Interact. 22:269-281.

Bos, J. I., Kanneganti, T. Ä., Young, C., Cakir, C., Huitema, E., Win, J., Armstrong, M. R., Birch, P. R., and Kamoun, S. 2006. The C-terminal half of Phytophthora infestans RXLR effector AVR3a is sufficient to trigger R3a-mediated hypersensitivity and suppress INF1-induced cell death in Nicotiana benthamiana. Plant J. 48:165-176.

Bos, J. I. B., Armstrong, M. R., Gilroy, E. M., Boevink, P. C., Hein, I., Taylor, R. M., Zhendong, T., Engelhardt, S., Vetukuri, R. R., Harrower, B., Dixelius, C., Bryan, G., Sadanandom, A., Whisson, S. C., Kamoun, S., and Birch, P. R. J. 2010. Phytophthora infestans effector AVR3a is essential for virulence and manipulates plant immunity by stabilizing host E3 ligase CMPG1. Proc. Natl. Acad. Sci. USA 107:9909-9914.

Boutemy, L. S., King, S. R. F., Win, J., Hughes, R. K., Clarke, T. A., Blumenschein, T. M. A., Kamoun, S., and Banfield, M. J. 2011. Structures of Phytophthora RXLR effector proteins: A conserved but adaptable fold underpins functional diversity. J. Biol. Chem. 286:35834-35842.

Bouwmeester, K., De Sain, M., Weide, R., Gouget, A., Klamer, S., Canut, H., and Govers, F. 2011. The lectin receptor kinase LecRK-I. 9 is a novel Phytophthora resistance component and a potential host target for a RXLR effector. PLoS Pathog. 7:e1001327.

Bradeen, J. M., Iorizzo, M., Mollov, D. S., Raasch, J., Kramer, L. C., Millett, B. P., Austin-Phillips, S., Jiang, J., and Carputo, D. 2009. Higher copy numbers of the potato $R B$ transgene correspond to enhanced transcript and late blight resistance levels. Mol. Plant-Microbe Interact. 22:437-446.

Champouret, N., Bouwmeester, K., Rietman, H., van der Lee, T., Maliepaard, C., Heipink, A., van de Vondervoort, P. J. I., Jacobsen, E., Visser, R. G. F., van der Vossen, E. A. G., Govers, F., and Vleeshouwers, V. G. A. A. 2009. Phytophthora infestans isolates lacking class I ipiO variants are virulent on Rpi-blb1 potato. Mol. Plant-Microbe Interact. 22:1535-1545.

Chen, Y., Liu, Z., and Halterman, D. 2012. Molecular determinants of resistance activation and suppression by Phytophthora infestans effector IPI-O. PLoS Pathog. 8:e1002595.

Dodds, P. N., and Rathjen, J. P. 2010. Plant immunity: Towards an integrated view of plant-pathogen interactions. Nat. Rev. Genet. 11:539-548.

Fabro, G., Steinbrenner, J., Coates, M., Ishaque, N., Baxter, L., Studholme, D. J., Korner, E., Allen, R. L., Piquerez, S. J., and Rougon-Cardoso, A. 
2011. Multiple candidate effectors from the oomycete pathogen Hyaloperonospora arabidopsidis suppress host plant immunity. PLoS Pathog. 7: e1002348.

Foster, S. J., Park, T.-H., Pel, M., Brigneti, G., Śliwka, J., Jagger, L., van der Vossen, E., and Jones, J. D. G. 2009. Rpi-vnt1.1, a Tm-2(2) homolog from Solanum venturii, confers resistance to potato late blight. Mol. PlantMicrobe Interact. 22:589-600.

Fry, W. E., Birch, P. R. J., Judelson, H. S., Grünwald, N. J., Danies, G., Everts, K. L., Gevens, A. J., Gugino, B. K., Johnson, D. A., Johnson, S. B., McGrath, M. T., Myers, K. L., Ristaino, J. B., Roberts, P. D., Secor, G., and Smart, C. D. 2015. Five reasons to consider Phytophthora infestans a reemerging pathogen. Phytopathology 105:966-981.

Haas, B. J., Kamoun, S., Zody, M. C., Jiang, R. H., Handsaker, R. E., Cano, L. M., Grabherr, M., Kodira, C. D., Raffaele, S., and Torto-Alalibo, T. 2009. Genome sequence and analysis of the Irish potato famine pathogen Phytophthora infestans. Nature 461:393-398.

Halterman, D., Chen, Y., Sopee, J., Berduo-Sandoval, J., and Sánchez-Pérez, A. 2010. Competition between Phytophthora infestans effectors leads to increased aggressiveness on plants containing broad-spectrum late blight resistance. PLoS ONE 5:e10536.

Huang, S., van der Vossen, E. A. G., Kuang, H., Vleeshouwers, V. G. A. A., Zhang, N., Borm, T. J. A., van Eck, H. J., Baker, B., Jacobsen, E., and Visser, R. G. F. 2005. Comparative genomics enabled the isolation of the $R 3 a$ late blight resistance gene in potato. Plant J. 42:251-261.

Jones, J., Foster, S. J., Chu, Z., Park, T. H., Van Der Vossen, E. A. G., Pel, M. A., and Visser, R. G. F. 2013. Late blight resistance genes and methods. Google Patents WO 2009013468 A3.

Jones, J. D., and Dangl, J. L. 2006. The plant immune system. Nature 444:323-329.

Kamoun, S., Furzer, O., Jones, J. D. G., Judelson, H. S., Ali, G. S., Dalio, R. J. D., Roy, S. G., Schena, L., Zambounis, A., Panabières, F., Cahill, D., Ruocco, M., Figueiredo, A., Chen, X.-R., Hulvey, J., Stam, R., Lamour, K., Gijzen, M., Tyler, B. M., Grünwald, N. J., Mukhtar, M. S., Tomé, D. F. A., Tör, M., Van Den Ackerveken, G., McDowell, J., Daayf, F., Fry, W. E., Lindqvist-Kreuze, H., Meijer, H. J. G., Petre, B., Ristaino, J., Yoshida, K., Birch, P. R. J., and Govers, F. 2015. The top 10 oomycete pathogens in molecular plant pathology. Mol. Plant Pathol. 16:413-434.

Karasov, T. L., Horton, M. W., and Bergelson, J. 2014. Genomic variability as a driver of plant-pathogen coevolution? Curr. Opin. Plant Biol. 18:24-30.

King, S. R., McLellan, H., Boevink, P. C., Armstrong, M. R., Bukharova, T., Sukarta, O., Win, J., Kamoun, S., Birch, P. R., and Banfield, M. J. 2014. Phytophthora infestans RXLR effector PexRD2 interacts with host MAPKKK $\varepsilon$ to suppress plant immune signaling. Plant Cell 26:1345-1359.

Kramer, L. C., Choudoir, M. J., Wielgus, S. M., Bhaskar, P. B., and Jiang, J. 2009. Correlation between transcript abundance of the $R B$ gene and the level of the $R B$-mediated late blight resistance in potato. Mol. PlantMicrobe Interact. 22:447-455.

Liu, T., Ye, W., Ru, Y., Yang, X., Gu, B., Tao, K., Lu, S., Dong, S., Zheng, X., and Shan, W. 2011. Two host cytoplasmic effectors are required for pathogenesis of Phytophthora sojae by suppression of host defenses. Plant Physiol. 155:490-501.

Lokossou, A. A., Park, T.-h., van Arkel, G., Arens, M., Ruyter-Spira, C., Morales, J., Whisson, S. C., Birch, P. R. J., Visser, R. G. F., Jacobsen, E., and van der Vossen, E. A. G. 2009. Exploiting knowledge of $R / A v r$ genes to rapidly clone a new LZ-NBS-LRR family of late blight resistance genes from potato linkage group IV. Mol. Plant Microbe Interact. 22:630-641.

National Potato Council. 2016. Potato Statistical Yearbook. http://www. nationalpotatocouncil.org/files/7014/6919/7938/NPCyearbook2016_-_FINAL.pdf

Pel, M. A., Foster, S. J., Park, T.-H., Rietman, H., van Arkel, G., Jones, J. D. G., Van Eck, H. J., Jacobsen, E., Visser, R. G. F., and Van der Vossen,
E. A. G. 2009. Mapping and cloning of late blight resistance genes from Solanum venturii using an interspecific candidate gene approach. Mol. Plant Microbe Interact. 22:601-615.

Petre, B., and Kamoun, S. 2014. How do filamentous pathogens deliver effector proteins into plant cells? PLoS Biol. 12:e1001801.

Pieterse, C. J., van West, P., Verbakel, H. M., Brasse, P. W., van den Berg-Velthuis, G. C., and Govers, F. 1994. Structure and genomic organization of the ipiB and ipiO gene clusters of Phytophthora infestans. Gene 138:67-77.

Romero-Calvo, I., Ocón, B., Martínez-Moya, P., Suárez, M. D., Zarzuelo, A., Martínez-Augustin, O., and de Medina, F. S. 2010. Reversible Ponceau staining as a loading control alternative to actin in Western blots. Anal. Biochem. 401:318-320.

Rovenich, H., Boshoven, J. C., and Thomma, B. P. 2014. Filamentous pathogen effector functions: of pathogens, hosts and microbiomes. Curr. Opin. Plant Biol. 20:96-103.

Schneider, C. A., Rasband, W. S., and Eliceiri, K. W. 2012. NIH Image to ImageJ: 25 years of image analysis. Nat. Methods 9:671-675.

Senchou, V., Weide, R., Carrasco, A., Bouyssou, H., Pont-Lezica, R., Govers, F., and Canut, H. 2004. High affinity recognition of a Phytophthora protein by Arabidopsis via an RGD motif. Cell. Mol. Life Sci. 61:502-509.

Song, J., Bradeen, J. M., Naess, S. K., Raasch, J. A., Wielgus, S. M., Haberlach, G. T., Liu, J., Kuang, H., Austin-Phillips, S., Buell, C. R., Helgeson, J. P., and Jiang, J. 2003. Gene RB cloned from Solanum bulbocastanum confers broad spectrum resistance to potato late blight. Proc. Natl. Acad. Sci. USA 100:9128-9133.

Thomma, B. P. H. J., Nurnberger, T., and Joosten, M. H. A. J. 2011. Of PAMPs and effectors: The blurred PTI-ETI dichotomy. Plant Cell 23:4-15.

Tsuda, K., and Katagiri, F. 2010. Comparing signaling mechanisms engaged in pattern-triggered and effector-triggered immunity. Curr. Opin. Plant Biol. 13:459-465.

van der Vossen, E., Sikkema, A., Hekkert, B. T. L., Gros, J., Stevens, P., Muskens, M., Wouters, D., Pereira, A., Stiekema, W., and Allefs, S. 2003. An ancient $R$ gene from the wild potato species Solanum bulbocastanum confers broad-spectrum resistance to Phytophthora infestans in cultivated potato and tomato. Plant J. 36:867-882.

van Poppel, P. M., Guo, J., van de Vondervoort, P. J., Jung, M. W., Birch, P. R., Whisson, S. C., and Govers, F. 2008. The Phytophthora infestans avirulence gene Avr4 encodes an RXLR-dEER effector. Mol. Plant-Microbe Interact. 21:1460-1470.

van West, P., de Jong, A. J., Judelson, H. S., Emons, A. M. C., and Govers, F. 1998. The ipiO gene of Phytophthora infestans is highly expressed in invading hyphae during infection. Fungal Genet. Biol. 23:126-138.

Vetukuri, R. R., Åsman, A. K., Tellgren-Roth, C., Jahan, S. N., Reimegård, J., Fogelqvist, J., Savenkov, E., Söderbom, F., Avrova, A. O., and Whisson, S. C. 2012. Evidence for small RNAs homologous to effector-encoding genes and transposable elements in the oomycete Phytophthora infestans. PLoS One 7:e51399.

Vossen, E. A., Gros, J., Sikkema, A., Muskens, M., Wouters, D., Wolters, P., Pereira, A., and Allefs, S. 2005. The Rpi-blb2 gene from Solanum bulbocastanum is an Mi-1 gene homolog conferring broad-spectrum late blight resistance in potato. Plant J. 44:208-222.

Wang, M., Weiberg, A., and Jin, H. 2015. Pathogen small RNAs: A new class of effectors for pathogen attacks. Mol. Plant Pathol. 16:219-223.

Yu, X., Tang, J., Wang, Q., Ye, W., Tao, K., Duan, S., Lu, C., Yang, X., Dong, S., and Zheng, X. 2012. The RxLR effector Avh241 from Phytophthora sojae requires plasma membrane localization to induce plant cell death. New Phytol. 196:247-260. 